\title{
Literature Review of Online Learning in Academic Libraries
}

\section{By: Tasha Maddison, Carolyn Doi, Shannon Lucky and Maha Kumaran}

\begin{abstract}
Online learning refers to instruction that is delivered electronically through various multimedia and internet platforms and applications. It is used interchangeably with other terms such as "online learning," "web-based learning," "e-learning," "computer-assisted instruction," and "Internet-based learning" (Ruiz, Mintzer, \& Leipzig, 2006). This chapter includes a review of the literature published between 2010 and 2015 on online learning in information literacy instruction in academic libraries. Information about the landscape of online information literacy instruction is presented including summaries about the technology used to create online instructional resources and the technology used to present and access online instruction. Both limitations and best practices relating to online instruction for information literacy are discussed.
\end{abstract}

